\title{
Editorial: On IRIE Vol. 25
}

India is the world's largest provider of IT services accounting for approximately 140 billion of revenues. The industry employs about 10 million workforces today. According to Google estimates, the Indian developer community will be the largest in the world by 2018.

While in the very beginning and rather stable for a long time India's competitive advantage was mainly being significantly cheaper India is gaining today more and more prominence also in terms of intellectual capital with several global IT firms setting up their innovation centers in India. Indeed, the IT industry has led to a fundamental transformation of the country concerning almost every sector: from economy to labour, education, science, politics and even culture and religion.

These two aspects of the development in India illustrate two very important issues for Information Ethics:

- Firstly, in contrary to the early discussion of the phenomenon called Digital Divide IT doesn't cement the separation of haves (of digital access in the Western world) and have-nots (in the rest of the world). It rather is one of the most powerful and fastest developing sources of value creation in human history.

- Yet, secondly, we observe another divide caused by the transformational power of the digital technologies equally important and demanding: the creation of privileged highly individualized workplaces on the one hand - allowing for self-fulfilment and self-control through the new technologies. And on the other hand, a precarious "cybertariat", which is just as online but online for labour virtually round the clock, mainly externally controlled by algorithms (be it in vehicles scheduled by Uber, be it in the high-tech warehouses of Amazon or offering their workforce on online exchanges on pay-asyou-go basis) without any social security against layoffs, unemployment or regarding their actual working conditions.

The latter change of paradigms raises questions that cannot be answered from classical business ethics. How shall our working world be organized under the circumstances of digitalization and subjectification? How can industrial democracy be transformed into a digital. What should it aim for? How can new forms of industrial action in digital capitalism look like?

The tearing pace of the development in India raises these questions at the utmost urgency. Nonetheless, under the subject "Ethics for Indian Cybertariats", Indian scholars have also initiated the necessary intellectual discussion to govern these issues and find answers to the questions posed by it. We are thankful that we can share this in this wonderful issue.

Sincerely yours,

the editors of IRIE 